\title{
Producing Authenticity: Urban Youth Arts, Rogue Archives and Negotiating a Home for Social Justice
}

\author{
STUART R. POYNTZ \\ Simon Fraser University, Canada
}

\begin{abstract}
Social justice needs a home, a place where it can be found, especially for young people growing up in fragmented and increasingly inequitable societies. Community youth arts organizations have secured a certain prominence in this context over the past three decades and are now part of the urban infrastructures that shape connected learning networks in highly industrialized nations. In this capacity, youth arts organizations regularly engage a language and aesthetics of authenticity and trust as part of how they call out, represent and make a home for children and youth. This paper examines how authenticity in youth culture and youth cultural expression is negotiated by arts organizations and how organizations locate their own trustworthiness as allies of young people through the curation of online media archives.

The analysis draws on the internet media archives of two youth arts organizations in Canada's largest English-speaking cities. The Oasis Skateboard Factory (OSF) in Toronto, $\mathrm{ON}$ is an extension program of the Toronto District School Board that enables participants to create their own brands and learn to run a skateboard or professional design business. ReelYouth (Vancouver, BC) started in Vancouver in 2005 as a community media empowerment project, and now delivers programs across Canada and internationally. The claims to youth authenticity articulated in each media archive reveal how authenticity and trust are negotiated ideologically by each organization and how organizations mark their ontological status, as a home from which young people can think and respond to an unjust world.

I examine how youth authenticity is produced by analyzing how discourses of youth identity, connection and trust are deployed across each archive. Whilst showcasing how authenticity is negotiated by each group, I show how the production of authenticity discourses by OSF and ReelYouth simultaneously convey a deeper reality: the way youth arts groups operate as care structures (Scannell, 2014) that offer ontological security (Giddens, 1991), and places of increasing "awareness of previously unnoticed interconnections" (Frosh, 2019, p. 16) for youth. In this way, they operate as sites of border work, places of routing from which the work of social justice can be borne.
\end{abstract}


KEYWORDS youth arts; non-formal learning; authenticity and trust; urban space

\section{Introduction}

Social justice needs a home, a place where it can be found. This is especially so for young people growing up in fragmented and increasingly inequitable societies, where the role of traditional sites of learning, including schools has undergone rapid change and where digital media are regularly a source of disruption and transformation, offering new sites of influence and persuasion and the "general broadening of risk-taking and risk-bearing as properties" of children's and youth's experiences (Appadurai, 2013, p. 3). A home in this context isn't a domestic space as much as it is a place for youth belonging, a site where "border work" happens, where young people are given opportunities to orient outward, to a larger world, to discover external relationships, negotiate identities and social skills and develop routes toward possible futures (Christenson \& O'Brien, 2003, p. 4).

Community youth arts organizations have secured a certain prominence in this environment and are now part of the urban infrastructures (Amin, 2014) that shape connected learning networks across highly industrialized nations (Ito et al., 2018; Poyntz et al., 2019). The roots of the youth arts sector go back to community organizing and community arts in the post-war era (Bekerman et al., 2005). Over the last 30 years, non-formal youth arts organizations have grown in significance as part of the general expansion of third sector, social service organizations under neoliberalism. Youth arts groups have developed as intergenerational spaces of trust, care and connection that aid youth transitions through adolescence by creating participatory spaces to negotiate citizenship and address digital divides in highly mediated cultures (cf. Poyntz et al., 2019). Youth arts augment the semiotic resources and learning available for young people through traditional schooling and are linked to the acquisition of key literacies and networks necessary for work and citizen participation in global capitalist societies.

In taking on this role in recent decades, youth arts organizations regularly engage a language and aesthetics of authenticity and trust as part of how they call out, represent and make a home for children and youth. Discourses of authenticity matter because they authorize the ground of youth belonging. Authenticity is a loose yet persistent signifier in young people's cultures, one that continues to function as a tool of social orientation and wayfinding for teenagers, while serving as a popular reference point for public debates about credible information sources and the integrity of media representations of young people. In this paper, I examine how authenticity and trust are negotiated by arts organizations in ways that mark their ontological status as a home from which young people can think and respond to an unjust world. 
The analysis draws on the internet media archives of two youth arts organizations in Canada's largest English-speaking cities and is part of Youthsites: The Non-Formal Learning Sector in Creative Lives, a five-year SSHRC-funded project examining the creative arts sector for socially disadvantaged youth in three global cities (London, Toronto and Vancouver). The Oasis Skateboard Factory (OSF) in Toronto, ON is an extension program of the Toronto District School Board that enables participants to create their own brands and learn to run a skateboard or professional design business. ReelYouth (Vancouver, BC) started in Vancouver in 2005 as a community media empowerment project, and now delivers programs across Canada and internationally. The OSF and ReelYouth internet media archives consist of a range of artifacts (more than 100 for each organization) and interfaces that collectively showcase each organization by curating youth-made media, national and regional mainstream news (print and video) coverage, blog posts and related participatory narratives, key research reports and other videos produced by and about the organizations between 2005 and the present. Collectively, each online collection functions as a rogue archive (De Kosnik, 2016), a non-traditional, non-canonical, specialized pool of media that articulates discourses of youth authenticity that helps to construct trust with key youth communities.

To understand how the archives mark youth arts groups as a home for social justice, I draw on Pauwels' (2012) social semiotic framework to examine each organization's media archive at two levels: (1) the technical and aesthetic interface on the homepage of each website; and (2) the language and aesthetics that dominate in the online searchable media archives of each organization. I examine how youth authenticity is produced by analyzing how discourses of youth identity, connection and trust are deployed across each collection. This deployment highlights how authenticity is ideologically negotiated by each organization; but, it also points to the way youth arts groups function ontologically, as spaces of provision, care and belonging for youth. Organizations perform this latter role by presenting persistent, durable and consistent modes of representation, by opening up access to the "real," by which I mean access to the means for reflective world disclosure (Kompridis, 2006) and by staging access to forms of social agility and renewed relationships with official institutions, including schools. In the process, groups like OSF and ReelYouth operate as care structures (Scannell, 2014) that offer ontological security (Giddens, 1991) and a place of increasing "awareness of previously unnoticed interconnections" (Frosh, 2019, p. 16) for youth. In this way, they operate as sites of border work, places of belonging and routing for the work of social justice. 


\section{Authenticity, Trust and the Youth Arts Sector}

Authenticity is a fluid and much debated concept frequently challenged for its utility in cultural analysis (Jenss, 2004). Notions of cultural authenticity have historically been used by figures like Adorno and Horkheimer to critique the sullying of culture by consumerism, mass society and capitalist commodification. Here, authenticity is associated with the fundamental qualities of a form of experience and inauthenticity is used to mark an adulteration or corruption of a primary mode of life. The problem with such critiques is that they tend to draw on essentialist notions that configure authenticity around the inherent qualities of a privileged form of culture or the "inherent quality of some object, person or process" (Vannini \& Williams, 2009, p. 2). In the wake of seminal texts like Peter Berger and Thomas Luckmann's (1967) The Social Construction of Reality and the influence of various postmodernisms, however, the influence of essentialist or realist conceptions of authenticity has waned and pragmatist or sociallyconstructed notions of authenticity have risen to the fore (Vannini \& Williams, 2009).

Driving these developments in youth studies and the sociology of childhood is the fact that authenticity remains a potent marker across consumer cultures, a measure of credibility for celebrities, brands and texts, and a wayfinding tool for teenagers in times of rapid socio-cultural and technological change. Framing authenticity as a socially situated phenomenon shifts the concept away from associations with purity or singular cultural identities, focusing attention instead on how authenticity operates as a powerful form of social orientation used to locate distinct youth identities, needs and experiences. As a marker of social orientation, authenticity "refers to a set of qualities that people in a particular time and place have come to agree represent an ideal or exemplar" (Vannini \& Williams, 2009, p. 3). Authenticity is something that emerges through acts of mutual understanding, collective efforts at identity performance and common perceptions of space, locality and shared "things" (Nayak, 2003). Authenticity is not an absolute but a conditional phenomenon, a mutable experience that nonetheless continues to function as a marker of community, connection and trust.

As emerging crises and risks have proliferated, questions of authenticity have become common in public culture. Contemporary debates about information access, the credibility of information sources and the development of online "echo chambers" (Bruns, 2019; Chun, 2016) have all heightened concerns about what media and cultural forms young people can trust. These worries have extended long-standing anxieties about cyber violence and "stranger danger" (Crooks, 2018; Poyntz, 2013), which, while often overstated have nonetheless fueled media panics (Drotner, 1999) about legitimate and authentic forms of online persuasion. Changes in young people's play cultures, the proliferation of risky online content, including 
pornography, and the advent of data surveillance powered by algorithms that incorporate young people into the global imaginaries of consumer celebrity cultures and the archives of surveillance states, have all amplified the feeling that conditions of authenticity, connection and trust are more precarious and important than ever. Even among online Instagram "influencers," authenticity - as opposed to popularity registered by "likes" - has emerged as a crucial element for sustaining relationships between cyber celebrities and their online communities (Abidin, 2018; Marwick, 2013). Concerns about authenticity and trust are compounded by insecurities surrounding changes in young people's working and learning lives, including the future threat posed by automation and growing skepticism about the fitness of modern institutions like schools to address the needs and hopes of youth (Sefton-Green \& Erstad, 2019).

Perhaps not surprisingly, novel sites of connected learning and media participation, including the youth arts learning sector, have gained prominence in this context. The youth arts sector is not often recognized as such, at least in part because the sector is not typically part of the remit of any one state ministry, secretariat or policy apparatus. It is a liminal space where the boundaries between institutions, policy fields, pedagogies, and subjectivities blur (Poyntz et al., 2019). The sector includes a number of institutional forms and kinds of programs, including alternative-to-school and after-school programs, initiatives connected to art galleries and stand-alone institutions and projects that can have a relatively short life-span, but are intended to engage risk conditions related to youth health, job training and skills development, the development of creative voice and identity concerns, and so on. Participants in youth arts organizations tend to be between 13 and 25 years of age. Funding generally comes from a cross-section of sources, including private and community foundations, government programs, private donations and fee-for-service programming (Poyntz et al., 2019; SeftonGreen, 2013). Organizations differ in size and in general, support forms of education that exist outside the mainstream curriculum, aesthetic expression and visions of civic participation that run against the grain and opportunities for socially marginalized young people who are frequently denied them. Youth arts organizations are often evaluated and monitored by local authorities at city level or even the nation state; and, projects typically fit within a complex network of routes for young people within learning institutions in the city.

The range and impact of youth arts organizations has expanded in recent decades as grassroots and non-governmental organizations have proliferated under neoliberalism and turned civil society into a site of struggle over the role of non-market-based activities and collectivities (Harvey, 2005; Poyntz, 2018). Soo-Ah Kwon (2013) marks the influence systems of neoliberal governance have had on the sector and our own work (Poyntz et al., 2019) has traced a series of paradoxes that continue to shape the sector. Among 
these paradoxes, the challenge of youth representation and recognition is an ongoing concern.

In most jurisdictions, the youth arts sector depends on alignment with social policy and funding priorities among a patchwork of government and third sector funding bodies to secure its future; and yet the relationship of the sector with these sources is vexed. Organizations are responsive to social policy, funding opportunities and dominant media representations about young people, and yet they're equally attuned to the differences between state, market and philanthropic interests and the rights and needs of youth. In a recent paper we noted the challenge this poses:

Youth arts organizations must develop a language to describe who it is they work with that is responsive to the agendas of funders and credible with youth participants. Yet, to negotiate this position is to tread paradoxically between the demands of external funders and respect for youth program participants. Labelling young people is a profound challenge for the sector, because 'deficit' labels that refer to patterns of 'exclusion' and 'vulnerability' risk pathologizing and 'othering' the very youth the sector wishes to support. Yet, it is just this language that constitutes the symbolic power of the sector among funders (Poyntz et al., 2019, p. 271).

Using the language of social policy and prominent media narratives to engage external support is hardly surprising. And yet, it is here, within this struggle over the production and representation of youth that questions of authenticity and trustworthiness play out. The media archives produced and maintained by youth arts organizations are an especially robust site of such negotiations, and in what follows, I examine how OSF's and ReelYouth's media archives produce a language and aesthetics of youth authenticity as part of situating their role as allies of young people and "a gathering force" in the social life of communities (Amin, 2014, p. 138).

\section{Reading Rogue Archives}

The internet media archives of organizations like OSF and ReelYouth offer a rich site to examine how authenticity and trustworthiness are curated online because media archives stage a public assemblage of artifacts that enunciate the identity, intentions, impact, allies and key voices tied to organizations over their history. Such collections are examples of what Abigail De Kosnik (2016) calls rogue archives, non-canonical, digital assemblages that are created about, "for and by highly specific communities" (p. 84). Rogue archives have proliferated as the affordances built into digital technologies enable more and more people to undertake archival projects. Such projects reflect a loosening of linkages between public memory and the state (Auslander, 2008), as new networks of public memory have developed, tied to groups and communities wishing to preserve "whatever content they 
[deem] suitable for digital preservation" (De Kosnik, 2016, p. 1). Internet media archives address the challenge of ephemerality for youth arts organizations, by offering a means and site for preservation of what has been done and what has been said about what has been done. In the process, they provide a rich site to interrogate how organizations like OSF and ReelYouth cultivate a sense of authenticity, connection and trust with youth.

The media archives of both OSF and ReelYouth are neither exclusive nor ideal representations of the organizations. They are expansive and dedicated to persistent publication, yet they are also selective (i.e., not all media produced by or about an organization is present), subject to breakdown (i.e., broken links) and support mid-term rather than long-term content preservation. They "stabilize and reproduce particular practices and forms of knowledge" (Lischer-Katz, 2017), and in this way work as counter-canons that don't represent everyone but recognize specific communities and forms of representation (De Kosnik, 2016, p. 75). Like most other community archives, OSF's and ReelYouth's archives are freely available, with artifacts that can be downloaded in their entirety and in general are not restricted by copyright.

What constitutes an organization's media archive is not straightforward in a time of incessant technology change and the rise and fall in popularity of specific platforms. Facebook pages, Instagram stories and Twitter flows are now part of the online ecology organizations curate to showcase and promote their work and connect with others. But are they part of an organization's media archive in the same way as a website sustained over years? The answer would appear to be yes, and yet how those spaces archive and "hold" the work of organizations is different than a proprietorial website. Of course, websites have become rather moldy in an era obsessed with technological futurism and FOMO (fear of missing out). Nonetheless, if we think of websites as spaces or even repositories of artifacts - text, sound, video files, and so on - that allow for minimal forms of interactive connection with users, then they perform a valuable archiving function for organizations that regularly struggle to keep up with persistent transformations in digital architecture.

In this paper, the analysis of the media archives of OSF and ReelYouth is limited to artifacts and experiences present on each organization's website (http://oasisskateboardfactory.blogspot.com/ and https://www.reelyouth.ca/), with a specific focus on the artifacts curated in the media forum sections of each site. In each instance, there are more than 100 artifacts, including award winning youth-made videos, radio interviews, print and video links to national and regional mainstream news coverage, blog posts, research reports and other visual media produced by and about the organizations between 2005 and the present. In the case of OSF, in addition to their home page, a pool of 40 artifacts were used as a representative example of the media archive, with particular focus on artifacts produced over the past seven years. Other artifacts were either unavailable because links were broken or were 
deemed repetitive (i.e., similar programs or genres of news reporting). In addition to ReelYouth's website homepage, a pool of 37 artifacts were selected, again focused on material produced since 2012, and similarly, other artifacts were either unavailable or were deemed repetitive (i.e., similar programs or genres of news reporting).

I am most interested in the way the archive of each organization produces aesthetic resources with symbolic power and resources that configure social identities and experiences of belonging. Pauwels' (2012) social semiotic framework for examining websites affords helpful tools to examine these foci at two levels: (1) the technical and aesthetic interface on the home page of each website; and, (2) the visual and audio language and aesthetics that dominate in the online searchable media archives of each organization. Pauwel's framework invites an examination of web objects and artifacts at multiple levels, including the material characteristics of the image (i.e., texture, resolution, sharpness, colour spectrum and so on); the signifiers and codes of static images (i.e., composition, lighting, camera distance, focus, etc.); the signifiers and codes of the shot (i.e., camera movements and shutter speed); editing choices within artifacts; audio signifiers; layout and design signifiers; and, internal absences (i.e., who is in and who is not in shots?, what are their relational positions?). Pauwels' framework is used to examine the design of each site, as a "look" with specific aesthetics, including the ways youth and youthfulness are referenced.

Within the available media archives, I examined how a sense of youth authenticity is produced by analyzing how the related notions of identity, connection and trust are curated online. I operationalized these categories by treating each as a social figuration produced through particular forms of representation. Identity was examined in relation to common patterns of youth representation, including the key roles (Who can you be?) proposed for young people. Connection was analyzed in relation to how semiotic resources are used to say where youth are (i.e., Where do they belong?) and what purpose each organization has for youth (How do they connect with youth?). Trustworthiness was investigated by looking at how dominant things, actions and the style or tone of artifacts suggest a sense of sincerity and honesty. Together, these foci explore the cultural expressiveness (What is there?) within each media archive. While the intended audience was also explored for each artifact, this research did not include an investigation of audiences' reading practices vis-à-vis each site, so questions of target audience were only minimally helpful in the analysis presented.

\section{Oasis Skateboard Factory, Street Culture and Real Worlds}

Oasis Skateboard Factory is an alternative-to-school design program that operates out of a space in Scadding Court Community Centre in the historically low-income, immigrant-centred neighbourhood between 
Kensington Market and Dufferin Grove in Toronto. The program has been in operation since 2009, participants are 16-18 years old and can earn high school credits over one-to-two semesters by creating their own brands and running a professional skateboard/design studio. The program is an extension of the Toronto District School Board, but it has all the markings of a youth arts program, operating outside the normal strictures of formal schooling. Participation is based on student interest, attendance is essential and in some sense is required and participants ( 26 per four-month program) come from across the city, including major suburban ring areas around Toronto. Activities run from 10:30 to 3:30 each day and are led by the program's founder, Craig Morrison, and educator, Lauren Hortie, both of whom trained in community education.

When one arrives at the OSF website, ${ }^{1}$ the first thing one encounters is the OSF banner, a simple black box with white text that includes the OSF name and the, text, "School/SK8 \& Street Art Design Services, located at Scadding Court Community Centre." Beneath that is what might be considered a program motto: "Why be bored in school? Go to a Skateboard School!" There are no menu buttons at the top of the homepage; rather, as a blogspot one scrolls down the page to find material on information sessions, open house dates, a calendar of events for the month(s) ahead and much more.

Scrolling down the homepage, very quickly the OSF logo appears in black and white in a street-graffiti style font. Below this there are images of student-made skateboards, images of youth examining materials for board construction with the text, "Student designers planning their next skateboard colourways by picking out custom dyed veneers in the @ roarockit warehouse today," and other images of OSF clients, including an image from The Toronto Star, announcing that "Justin Bieber gets 14 new skateboards created by Toronto students," alongside an enlarged hashtag for \#altmfg, that references an alternative design, manufacture and distribution network in Toronto, of which OSF is a part. There are links to the OSF Online Shop, a series of text links, announcing that OSF was selected \#1 on The Toronto Star's Coolest Schools List in 2011, Hottest on Now Magazine's (Toronto's main alternative weekly) "Barometer" in 2012 and a series of other awards, including a Status of Women award in 2012 for Lauren Hortie and an Arts Educator of the Year award (2012) for Craig Morrison. Scrolling down further, there are a series of images of students, representing a diversity of genders and ethnicities. Some students flash gentle gang signs, including the ILY sign meaning, "I Love You." Other images capture the students in a group, wearing custom-designed, Indigenous-inspired hoodies, walking with boards through the streets of Toronto. Moving down further, there is reference to a thank you for a collaboration with elders from Nunavut, the

\footnotetext{
${ }^{1}$ The quotations, notations and references about Oasis Skateboard Factory in this section are taken from blog posts, videos, news reports, public relations documents and other texts contained in the organization's archive, during the period from August 01-September 30, 2019. The specific source of each reference is typically indicated in the text.
} 
Innu-dominated territory in Canada's north. There is a movie-like poster under the heading, "Class Portrait Double Feature by Anomaly 2018." The poster reads, "They came from The Factory" in green gooey horror film-like text. Students from the previous year's class are portrayed in the poster as zombies and other characters from an imaginary horror film. Other posters from earlier years appear with the slogan "The youth are revolting." Program partners' and community collaborators' logos appear and include the Toronto-Los Angeles creative agency, Anomaly, Roarocket, Concrete Wave Magazine, Evolve Skate Camp, Manic Coffee, Ridenorth: Canadian Skate Culture and various other skateboard brands and logos. There are at least two images of Craig Morrison and Lauren Hortie, neither of whom strike poses as typical educators. Craig has a full beard, looking like an aging hipster and both he and Lauren strike the looks of indignation common to boarding culture while holding boards and again, throwing mild gang signs. There is an upcoming events and announcements list, and then below that an extensive archive of articles, news reports and so on under the heading, "OSF in the Media ..."

Collectively, the language and aesthetic of the home page is clean, with ample use of white space, allusions to street graffiti and street culture, reference to a diversity of young people and key allies and program support networks. There is a sense of cool entrepreneurialism about the space that references brands, logos, celebrities and events while underplaying signifiers - like grades, assignments and so on - common to formal schooling. Importantly, the blogspot works in the sense that it functions seamlessly in a way that contrasts with the formal and sometimes spotty experience of many public school websites.

The media archive on the OSF site is a rich trove of artifacts that produce a language and aesthetics of youth authenticity by curating conceptions of identity, connection and trust. Among the 40 artifacts examined were: profile videos from Daily Vice and the YTV show, The Zone; a music video for OBEY clothing, featuring artist Shepard Fairey; a short documentary made by OSF; a documentary on Craig Morrison; magazine profiles and listings from Spacing independent urban magazine; a blog post by international artist, Mark Tirchner; many advocacy oriented news media articles from mainstream dailies in Canada; an OSF course listing from the Art Gallery of Ontario; several student videos; student-produced articles from Concrete Wave Magazine; and a single $\mathrm{CBC}$ radio interview featuring Laurie Hortie.

To make sense of how youth identity is curated in the collection, it's helpful to locate the youth we see and learn about, key youth allies and the roles proposed for young people. Across the archived media there is a range of youth presented, representing a cross-section of genders, ethnicities and apparently socio-economic classes who come "from across the city"; but, there is also clear recognition of - a calling out to - specific youth identities. Those identities include "punk rock types and skater dudes," but also "girls into skateboarding, ... graffiti artists and tattoo artists," some kids who are 
into writing, youth who "often come from challenging backgrounds and haven't had a good go of it in school," teens trying to "break out of the school mode," "kids that just wouldn't be in school, they would have dropped out," and "kids who are anxious to get out in the world and make their mark." Not surprisingly in an alternative-to-school program, OSF hails teens who have "fallen through the cracks," kids who don't succeed in school and sometimes represent the first in family to graduate from high school. The address to particular youth identities is reinforced through associations with key youth allies, including the aforementioned Shepard Fairey and Mark Tirchner, internationally renowned artists who bridge divides between street/public art, graffiti culture and the worlds of contemporary art. While recognizing particular youth identities, the roles proposed for young people in the media archive focus on becoming a young creative, an entrepreneur, artist and designer ("They are designers now") with a distinct brand or design identity. Taking on these roles is in turn presented as a way for young people to be "out in the world," to discover "talent you didn't know you had" and to become world-oriented or "engaged in real life."

A particular form of connection is curated in the media archive through semiotic resources that frame a sense of where youth are and the purpose of OSF for young people. Together, these elements configure a vernacular of belonging for youth. Not surprisingly, this syntax is oriented around specific forms of public space - a public skate park, a non-traditional classroom, the "inner-city arts community," particular "creative" neighbourhoods in Toronto, including Queen Street West and Kensington Market. But it also includes hidden spaces, like a site,

Tucked down a dumpster-blocked laneway off of Dufferin ... [where] the Oasis Skateboard Factory Pop-Up was a-buzz with participating student entrepreneurs, supportive friends and family, Toronto Design Offsite attendees and maybe one or two lured in with the promise of free Glory Hole Doughnuts. (Oasis Skateboard Factory pops up at the Baitshop, 2013)

Glory Hole Donuts is an upmarket Toronto shop offering traditional and artisanal fare that in many ways sits in the sweet spot of OSF's appeal: as a program for kids who lack social and cultural capital that promises experiences of class uplift.

A sense of connection is also constituted through the value proposition OSF presents for youth, much of which is tied to a promise of access to the real (world) and to valued subject positions by learning to build skateboards. Participants learn to build personal brands to promote self-development and real-world experience: "they are building their own brands, learning how to run a business. We have lots of pop-up shops, we sell everything we make and we get hired by clients to do jobs for them" (Craig Morrison). They reimagine high school as a skateboard company, treating participants "not as empty vessels but as equal partners who have something to offer" (Craig Morrison). They disrupt youth stereotypes: "we are reconnecting kids with 
something that got them in trouble: graffiti and skateboards, things that adults don't like" (Craig Morrison). They give students a route forward, providing real world skills, helping student creators to find their market and run a design company.

Kids learn "to work with clients ... doing high quality work, and making sure a job is done in a way that creates the next job" (Craig Morrison). They awaken untapped creativity, teach professionalism and focus on real life and doing something in the real world, "where things count." They open networks and value kids as creative workers (e.g., partnering with ad agencies including Anomaly in Toronto). "No one hands me something that I only mark and put in a folder. Everything we do is public: in the street, in a gallery, in pop-up shops, and at product launches" (Craig Morrison). By providing on-the-job experience, they legitimize kids with adult creatives and open up job placements. They also have a commitment to social justice. "We often talk about who you want to work with ... a big corporation that doesn't pay its workers well or with a small coffee shop that deals in a direct trade model. They are meeting other young people in these jobs and they start to see themselves having a place in the working world" (Craig Morrison). By "seeing their work acknowledged by the broader community, students begin to see themselves as participants in the city" (Craig Morrison).

In addition to addressing specific youth identities and discourses of connection, the archive produces a sense of youth authenticity by curating a catalogue of dominant things, actions and a style or tone that together signify the trustworthiness or sincerity of OSF. The single most important thing used to signify the trustworthiness of the organization is the skateboard, which is referenced across the archive, as the object of work and the site of creative self-expression, innovation and style. The skateboard is an object of transformation and the platform on which youth expression is actualized. In a Globe and Mail article from December 6, 2013, for instance, we read about "Hannah Duncan, a soft-spoken 18-year-old with hot pink hair, [who] shows off her design based on Salvador Dali's The Persistence of Memory, with melting skateboards in the place of the painter's iconic clocks" and "Cassidy Edwards, 18, [who] gives a report on the progress of her posterized design of Michelangelo's David." (Krashinski, 2013). In the same article, we're told about "another board with a take on Botticelli - except this time, Venus is born on a clamshell covered in sweet tattoos." Other things, including the unorthodox learning space, the skatepark outside Scadding Court Community Centre, a large mural for OBEY clothing, are also present. But the skateboard is unquestionably the dominant thing in the archive, a transformative object both common to youth culture and a signifier of new beginnings, new relationships, new opportunities and possibly even a new self. Among the many images in the archive, there is an otherwise bland artifact called "Dare2Create Art and Film" which includes images of youth producing their own boards. Among these there are two images which show representations of the youth creators fashioned on to their boards. In one of these examples, 
there is a before and after shot of a young woman, showing her as she was and as she has become, the board providing platform and inspiration for a reimagination of self.

The dominant style and tone evident among the artifacts tend to reinforce the significance of skateboard culture. Some of the mainstream news articles and videos tend toward the informational and advocacy for the program, but a series of videos, urban magazine articles and blogs highlight a street culture aesthetic through electronic music, hip hop, urban scenes, shots of skateboard parks, graffiti and massive urban murals. The power of these signifiers is only enhanced by the presence of specific celebrities, including the massively popular Toronto artist (and basketball ambassador), Drake, who along with Shephard Fairey, is presented as an ally of youth and if not a representative of OSF, at least a testament to the integrity and credibility of the program.

Collectively, then, the language of youth authenticity assembled within OSF's media archive is anchored around the appeal of creative expression, entrepreneurialism and the power of branding as an exercise in self-creation and commercial development; the power of transformative objects, most especially the skateboard; the power of youth voice and the diversity of youth voices; the democracy of talent; and the credibility of celebrity. The organization offers the prospects of class uplift, as has long been the mandate of public education systems, for a range of kids who have otherwise been failed by the mainstream school system, as well as alternative routes to adulthood and to future education. In this historical moment, when the lure of creative economies, creative careers and even youth voice has become common in learning economies around the world, some of this will not be surprising. Yet, how the organization stakes its claim to credibility among youth is not limited to these elements. Like ReelYouth, the power of organizations like OSF has as much to do with the ontological security they afford as it does their ideological calling out to youth. I return to this theme below.

\section{ReelYouth and Youth Citizens}

ReelYouth differs from OSF in many ways and yet there are important similarities. ${ }^{2}$ The organization started in 2005 in Vancouver, is a youthserving project and is now organized around four program areas: the ReelYouth Film Festival held annually and featuring youth-made films from across Canada; an innovative intergenerational program that brings together youth and seniors to produce videos about the experiences of each group; a series of social justice-oriented programs; and, a professional film production

\footnotetext{
${ }^{2}$ The quotations, notations and references about ReelYouth in this section are taken from blog posts, videos, news reports, public relations documents and other texts contained in the organization's archive, during the period from August 1-September 30, 2019. The specific source of each reference is typically indicated in the text.
} 
program. Of these initiatives, the first three predominate, but interestingly, in the media archive the artifacts most often address ReelYouth's intergenerational and social justice programs. Unlike OSF, ReelYouth operates in urban and rural regions and in recent years has produced programs ranging in length from one-to-four weeks across Canada. The annual Reel Youth Film Festival screens short films made by young people under 20 and tours in partnership with youth media organizations, high schools, community groups and other film festivals. Much of ReelYouth's funding comes from fee-for-service partnerships with community groups, school boards, Indigenous nations and community foundations. The founding director, Mark Vonesch, continues to lead the organization, working with production mentors, some of whom had previous experience as participants in ReelYouth projects. Youth participation is voluntary and based on interest.

The ReelYouth website has a very different feel than OSF. Where the latter is linked to skateboard culture, ReelYouth strikes a more grassroots, alternative tone. A drawn graphic of a young women of colour in a loosefitting skirt, holding a camera and looking out at the website user is prominent, while above her is the ReelYouth logo, scripted in a slightly childlike font that reminds one of Dr. Seuss. The same font is used for the menu buttons at the top and side of the page, which link (at the top) to sections on Programs/International Projects/Gallery/Media/About Us/Donate. To the left of the page the menu buttons link to sections for Home/Submit Your Film/Film Festival/Tour/Resources/Sponsors. Beneath the top menu links are a series of hyperlinked text blocks of varying sizes that are presented using more conventional fonts, with varying realistic images and colours behind the fonts. These block hyperlinks take users to: the 2019 ReelYouth Film Festival page; the ReelYouth Twitter feed; and, the ReelYouth Film Festival at the Vancouver International Film Festival. Beneath this, another series of hyperlink blocks take users to a series of recent projects, including: Prince George Claymation Programs; the sign-up for a Mississauga, Ontario film program; the film release for a Vernon, B.C. program; the Troublemakers 4.0 program, which is framed with rainbow colours; a program for LGBTQ Indigenous Youth; and, the film release for a youth and elders documentary program hosted in the remote northern community of Gjoa Haven, Nunavut. Other than these links, white space predominates, creating a clean if grassroots feel across the site. No other logos or brand tie-ins appear on the homepage, except for customary links to Facebook, Twitter and Youtube where visitors are invited to "follow us."

Similar to OSF, the media archive page for ReelYouth is the repository of a range of artifacts, including (in summer 2019) a remarkable documentary placed at the top of the page and pulled from the general collection, called: If Teardrops Were Pennies: Julia Cockney, an Elder of Tuktoyatuck. There is a series of videos from the Troublemakers 4.0 social justice program that portrays an incredible range of activists, artists and identity switchers in a manner that both locates difference and subsumes difference into the human 
family. There is a feature profile on young ReelYouth filmmakers working with homeless seniors originally broadcast on CBC television's anchor newscast, The National; a series of informational mainstream news stories about ReelYouth; a range of news articles from daily and weekly newspapers from across the country; articles from a Chinese language press outlet in Vancouver; a CBC local radio interview; and, an article from the queer weekly paper, XTRA Vancouver.

To make sense of how youth identity is curated in this collection, again it is helpful to locate how youth are represented and the key youth allies and roles proposed for young people. Like OSF, among the artifacts there is a range of youth presented, representing a diversity of genders (including non-binary youth), ethnicities and sexualities. But Indigenous and refugee or migrant youth are more visibly present here. So too interestingly are the number of visibly white youth, reflecting the fact that the organization often works in rural regions across Canada. In general, student filmmakers make up the majority of youth represented and importantly, many are revealed to have experience with the kinds of precarity (e.g., homelessness, isolation within their communities) explored in ReelYouth projects. Adult allies tend to be less obviously well-known media figures or artists and yet their connection with young people is often represented as quite profound. For instance, in a very simple dialogue, filmed over a black screen backdrop in a Troublemakers 3.0 documentary, we meet Sekani Dalkeith, a native transgender rights activist who engages in a rich dialogue of discovery, memory and hope with Jacoby MacDonald, a queer/questioning youth. In other documentaries, we meet Morgane Oger (Moving Forward), a trans activist and human rights advocate from Vancouver and in Endurance, we meet Jane Eaton Hamilton, a transgender photographer and artist. The aforementioned Julia Cockney is a remarkable Indigenous elder who among other things, presents the land as a place of respite, imagination and discovery for young people. Beyond this, the self-effacing humour and strength of a host of other adult allies - white seniors, Indigenous leaders and political activists - hail young people through moments of care and attention, irony and acts of leadership and survival. In this context, the roles proposed for youth focus on becoming change agents, leaders, storytellers and witnesses for marginalized and under-represented communities who reveal specific realities "about living in Canada and their vision of Canada." Young people are represented as figures of hope, who can learn to be "part of a culture," including cultures that have otherwise been ignored and abused in the past and remain deeply vulnerable today.

In a manner different from OSF, a sense of connection is curated in the ReelYouth media archive largely through semiotic resources that frame a sense of where youth could be, as opposed to where they are. There are in fact few instances of what might called youth spaces (youth bedrooms, sport facilities, etc.) visible in the archive. Rather, a series of videos highlight the land, as conceived and experienced in Indigenous cultures as spaces of 
imagination where youth can be with cultures that are otherwise possibly unknown to them. What otherwise might be considered mundane spaces, including seniors care homes and the homes of Indigenous and nonIndigenous elders, are likewise presented in ways that hail youth through prospects of discovery. Isolated, invisible city spaces, including stairwells, hidden sleeping quarters in city bushes and urban alleys in small communities are portrayed as sites of connection where youth are presented with opportunities to see and experience worlds around them that they might not otherwise know exist. More common sites of learning, including nontraditional classroom learning spaces and community centres are present, but a sense of connection through place is most commonly constructed through the introduction or re-imagination of new spaces and settings where youth are invited to engage and represent the world around them.

ReelYouth addresses young people through a value proposition that emphasizes the power in disrupting stereotypes and engaging with people and issues that appear under-represented in mainstream news reporting. Learning a host of media production and animation skills is clearly part of what is put on offer, but these skills are represented as in the service of something presumed to be larger and more socially and politically significant: the opportunity to develop intergenerational communication. "We can't build understanding between generations if we don't have the different generations present in the same room" (Mutya Macatumpag, Reel Youth program mentor). Media skills are also intended to foster connections across communities, particularly among communities that may otherwise be invisible to youth (e.g., those experiencing housing precarity, Indigenous elders, seniors, queer and trans activists) and to develop youth's voices in ways that help teens to reimagine the significance of the past and to reframe personal and social possibilities for the future. In short, the value proposition presented by ReelYouth's archive addresses the power of inclusion and the conditions needed to ensure a more socially just future. Together, the promise of where youth could be, alongside powerful value propositions about the potential impactfulness of young people construct a sense of belonging in ReelYouth's media archive that anchors youth authenticity around the merits of an engaged life.

While calling out to youth identities and discourses of connection, the archive sustains a sense of youth authenticity by curating a catalogue of dominant things, actions and a style or tone that together signify the trustworthiness or sincerity of ReelYouth. Among these, while no single object dominates as does the skateboard in the OSF archive, there is a dominant style that seems aimed at conveying the sincerity of the organization. Documentary realism is evident in a series of news stories, advocacy videos, video conversations, and portraits of various youth and adult figures across the archive, in ways that suggest a high degree of integrity, honesty and craft. Whether in the form of an extended CBC documentary on ReelYouth's homeless senior-youth program, a newspaper 
story about the documentary film, I am Hitkoak, that recounts the life, culture and land of elder, Alice Ayalik Hitkoak, or in numerous news stories (video and print), realism and the use of the camera as a window onto new worlds predominates. This style lends a sense of constructed transparency to the archive, as though here we are invited to find myriad efforts to convey faithfully worlds that otherwise lack the attention they deserve. This style suggests a kind of naïve innocence about what documentaries can do to open up the world, especially in an age of misinformation, fake videos and intense visual and audio distraction; but, this style and tone, alongside the playful innocence of ReelYouth's home page, convey a sense of integrity and trust, a hope that with more young people behind the camera, a more authentic and just world may prevail.

The language of authenticity produced through ReelYouth's media archive is clearly about young people as citizens, actors in the world who are capable of witnessing and fomenting social change. In a manner, this is different from OSF, but only in the sense that ReelYouth explicitly interpolates young people as change agents, whereas OSF addresses youth as participants in the world, as actors who have a legitimate and deserving place in the city. ReelYouth's claims to credibility, in other words, rest on a more explicit claim: that youth are not merely actors, but leaders of social change, partners with adults who can benefit from media skills in a time when social transformation runs through the screen and systems of media circulation orient our lives.

\section{Youth Arts, Continuity and World Disclosure}

The claims to youth authenticity articulated in the media archives of OSF and ReelYouth are different in style, content and possibly intention; and this is to be expected. Each organization has linked their credibility to a language and aesthetics of youth culture in ways that offer promise for young people, including identities around which youth participants can link their experiences and hopes for the future. OSF foregrounds the allure of entrepreneurialism, the appeal of the creative artist and work in the creative economy, networks of local businesses and alternative production associations, celebrities tied to Toronto and international public art and the allure of city space and the street as public places that in ideal circumstances are open to all. As a discourse of youth authenticity, OSF's ideological appeal runs through the semiotics of consumer cultures, neoliberal subjectivities (i.e., the creative entrepreneur) and the imaginative prospects of youth style; and yet, at the same time, OSF hails young people as participants in the city, actors who have a right to be in public and whose culture of graffiti, electronic music and street art is not only fit for the times, but a creative source for future self-realization. 
ReelYouth's media archive curates a somewhat different aesthetic and symbolic language of youth authenticity. Their appeal is linked to citizen learning, to the power of the camera as a truth-sayer and to the appeal of diversity and inclusiveness among young people and within society at large. Their credibility rests on the provision of digital skills, the allure of youth voices, especially among and for those marginalized from mainstream publics, access to people and communities woefully under-represented in the mainstream media and the power of documentary realism combined with a semiotics of transparency meant to open up windows onto the world. A spirit of innocence frames the language of youth representation in ReelYouth's media archive, combined with mild irony and the activist's sense of urgency and earnestness. News media formats dominate, as opposed to the semiotics of youth consumer cultures; and, perhaps more clearly than OSF, ReelYouth foregrounds the allure of social change in its appeal to young people.

While differences are apparent in each media archive, then, both channel ideological representations of young people that are hardly uncommon today. In their own ways, each rogue archive constructs visions of youth authenticity that while specific to Canada (especially with references to Indigenous cultures), will be familiar in many regions, testifying to the way globalization has inscribed youth cultures everywhere. The place-making or ground each organization offers for social justice struggles is not, however, linked to ideological representations alone. It is also and more significantly linked to the way authenticity discourses in each archive represent the ontological function of community arts groups, as spaces of provision, care and belonging for youth. This ontological ground is apparent in continuities that appear across each archive, continuities that point to how the youth arts sector itself has emerged as a critical provisioning infrastructure in a time when traditional institutions, including schools, have frequently failed young people and the challenge of youth transitions is as uncertain as it has ever been.

One of the principle commonalities across the two media archives is the presence of durable, persistent and consistent modes of youth representation. By durable in this instance, I mean to draw attention to the materiality of the archives as technical resources, records of happenings that provide a form of historical memory for each organization. As the preceding research indicates, the degree of durability and permanence within each archive is concerning. Some links fail, the visual interface of each site can change and the very significance of website-based archives can become moldy. But whether as website, cloud or a public social media newsfeed record (Robards et al., 2018), the medium-term durability of each media archive produces a durable place of being-in-the-world for and about youth that in turn provides a record of permanence. This is a significant value of rogue archives more generally and in the case of OSF's and ReelYouth's collections, they instantiate a technical record that can be found and searched (in some sense) in a way that 
provides a substantive and extended public record of youth cultural production.

Adding to the significance of these records as objects is the fact that they maintain a degree of stylistic and semiotic consistency directly tied to the organization itself. In this way, they mark a mode of youth being-in-theworld, a social and symbolic space of identity construction and orientation that maintains continuity over time. The media archives of OSF and ReelYouth are in a sense metonymic of the organizations as a whole: they are durable, persistent spaces of continuity that resist the general ephemerality of media culture, even if they are challenged by the same; they afford sites around which young people and others can gather; and, in this way, they constitute care structures (Scannell, 2014) that contribute to a sense of ontological security by affording a valve against the failure of traditional modernist institutions of youth provision and a point of future orientation on the world.

In affording sites of ontological refuge, OSF's and ReelYouth's media archives also share a commitment to providing access to the "real" for young people. They stage this commitment in diverse ways, some of which are shared, some of which are specific to each group. OSF regularly asserts their commitment to student work oriented to the real world, real creative networks, real design contracts, a real creative practice in the form of a skateboard and design studio and their concern for a visual language of the real street, rather than the classroom. ReelYouth's commitment to the real is implicated in the organization's name, but the archive stages the organization's commitment more explicitly through youth-made documentaries about real people and vulnerable communities and a language of documentary realism meant to bring into the light unknown experiences and communities. These commitments matter but I want to make a stronger argument: they matter not simply (or merely) because of their ideological significance, as issues and connections to which young people might attend. Rather, they matter because they signal how each archive (and by extension, each organization) orients youth to a horizon of realness, thereby affirming a normatively shared and valued place for youth in struggles over the real.

By producing and affirming a felt sense of the real among young people, in their own ways, OSF's and ReelYouth's media archives provide access to the means for reflective world disclosure (Kompridis, 2006). I mean that they afford a site where the "palpable materiality," the real-ationality of the world is made open for attention by youth (Frosh, 2019, p. 12). Through their attention to the real, each organization renders into significance the conditions and elements of realness itself, the ground or round-about-me-ness of the world, in a manner meant to resonate for youth while demanding a response, action or an address. This is the starting point for social justice, a call and expectation to understand and act on the world. In a time of uncertainty around youth transitions, finding a space that opens up the prospect of such an address, that affords an affective relationship with the 
round-about-me-ness of the world is a vital contribution for youth and for building social justice infrastructures in community.

Finally, amidst the normatively framed ontological security constituted within OSF's and ReelYouth's media archives, they also overlap in the way they stage offerings of social agility and forward movement for young people, particularly in regard to the recalibration of relationships with powerful institutions of youth provision like schools, the media and work. Both archives (and organizations) stake their credibility with youth at least in part through a recognition of the challenges young people face in a time of constrained and inequitable social resourcing, unstable and shifting work environments, ongoing youth identity crises and so on. This unstable environment is addressed differently by each organization, but across these differences common ground is evident in the way each organization constitutes a space of social transition, a home place for youth to stand in order to reconstitute powerful institutional relationships. This is evident across OSF's appeal to youth as a space for those who have "fallen through the cracks" and in the record of youth transitions to post-secondary school and viable work environments present in the archive. In ReelYouth's archive, social agility is staged through activists', seniors' and Indigenous leaders' stories. The significance of these records, however, has less to do with the particular claims any one statement presents, than with the way they collectively help youth orient to the world of power. The range of stories, complex narratives and statements about official institutions matter, but it is the collective contribution they make as a form of routing, a kind of social lineament or configuration oriented toward the future that is very much designed to enable young people to engage and respond to traditional institutions of power. In this way, OSF's and ReelYouth's media archives and the organizations themselves present collective spaces of ontological security, a home for border work to refocus and reimagine the disclosure of the world in a time when crises and rapid social, technical and political change make these kinds of spaces precarious and harder than ever to find.

\section{Conclusion}

Community media archives hold together forms of public memory that can and often have disappeared into the bottomless depths of the past. They offer a record of curation and cultural production that enables groups, like youth arts organizations to manage their own historicity and showcase their role as urban infrastructures of youth provision. Their significance is at least in part in the way they manifest a record of happenings that have both ideological and ontological significance. In the current historical moment, as questions of youth authenticity and trustworthiness have become popular in youth culture and in discourses about youth culture, it is significant that the youth arts sector has emerged as a vital if often invisible space of practices that support 
young people to question, critique and engage practices of injustice and opportunity. In this way, the sector affords a kind of home for young people, a durable place of trust and negotiation in fragmented and inequitable societies, where young people's connectivity with the present is brought into view and routes for addressing the demands of social justice are opened.

\section{Acknowledgements}

This research was supported by the SSHRC Insight Grant, Networks of Nonformal Learning: The State, Youth as Cultural Producers and Creative Life Pathways.

\section{References}

Abidin, C. (2018). Internet celebrity: Understanding fame online. Emerald Publishing. Amin, A. (2014). Lively infrastructure. Theory, Culture \& Society, 31(7/8), 137-161.

Appadurai, A. (2013). The future as cultural fact: Essays on the global condition. Verso. Auslander, P. (2008). Liveness: Performance in a mediatized culture. Routledge.

Bekerman, Z., Burbules, N. C., \& Silberman Keller, D. (Eds.). (2005). Learning in places: The informal education reader. Peter Lang.

Berger, P., \& Luckmann, T. (1967). The social construction of reality: A treatise on the social construction of knowledge. Doubleday.

Bruns, A. (2019). Are filter bubbles real? Polity Press.

Christenson, P., \& O'Brien, M. (2003). Children in the city: Introducing new perspectives. In P. Christenson \& M. O’Brien (Eds.), Children in the city: Home, neighbourhood and community (pp. 1-12). RoutledgeFalmer.

Chun, W. H. K. (2016). Updating to remain the same: Habitual new media. MIT Press.

Crooks, H. (2018). Reel girls: Approaching gendered cyberviolence with young people through the lens of participatory video [Unpublished doctoral dissertation]. University of Ottawa, Ottawa, Canada.

De Kosnik, A. (2016). Rogue archives: Digital cultural memory and media fandom. MIT Press.

Drotner, K. (1999). Dangerous media? Panic discourses and dilemma of modernity. Paedogogica Historica, 35(3), 593-619.

Frosh, P. (2019). The poetics of digital media. Polity.

Giddens, A. (1991). Modernity and self-identity: Self and society in the late modern age. Polity.

Harvey, D. (2005). A brief history of neoliberalism. Oxford University Press.

Ito, M. (2018). Affinity online: How connection and shared interest fuel learning. New York University Press.

Jenss, H. (2004). Dressed in history: Retro styles and the construction of authenticity in youth culture. Fashion Theory: The Journal of Dress, Body and Culture, 8(4), 387-403.

Kompridis, N. (2006) Critique and disclosure: Critical theory between past and future. MIT Press.

Krashinski, S. (Dec 6, 2013). Oasis Skateboard Factory gives struggling teens a chance to show their skills. The Globe and Mail. Retrieved from https://www.theglobeandmail.com/news/toronto/oasis-skateboard-factory-gives-strugglingteens-a-chance-to-show-their-skills/article15810072/\#c-image-0

Kwon, S.-A. (2013). Uncivil youth: Race, activism and affirmative governmentality. Duke University Press.

Lischer-Katz, Z. (2017). Studying the materiality of media archives in the age of digitization: Forensics, infrastructures and ecologies. First Monday, 22, 1-22. 


\section{Stuart Poyntz}

Marwick, A. (2013). Status update: Celebrity, publicity and branding in a social media age. Yale University Press.

Nayak, A. (2003). Race, place and globalization: Youth cultures in a changing world. Oxford University Press.

Oasis Skateboard Factory pops up at Baitshop (January 28, 2013). Retrieved from https://www.blogto.com/sports_play/2013/01/oasis_skateboard_factory_pops_up_at_the_b aitshop/

Pauwels, L. (2012). A multimodal framework for analyzing websites as cultural expressions. Journal of Computer Mediated Communication. 17, 247-265.

Poyntz, S. R. (2013). Public space and media education in the city. In P. Fraser \& J. Wardle (Eds.), Current perspectives in media education - Beyond a manifesto for media education (pp. 91-109). Palgrave Macmillan.

Poyntz, S. R. (2018). Vancouver youthspaces: A political economy of digital learning communities. In M. Dezuanni, M. Foth, K. Mellan \& H. Hughes (Eds.), Digital participation through social living labs: Valuing local knowledge, enhancing engagement (pp. 277-297). Elsevier.

Poyntz, S. R., Coles, R., Fitzsimmons-Frey, H., Bains, A., Sefton-Green, J., \& Hoechsmann, M. (2019). The non-formal learning sector, youth provision and paradox in the learning city. Oxford Review of Education, 45(2), 258-278.

Reel Youth. (n.d.). https://www.reelyouth.ca

Robards, B., Lincoln, S., Pinkard, B. C., \& Harris, J. (2018). Remembering through Facebook: Mediated memory and intimate digital traces. In A. S. Dobson, B. Robards \& N. Carah (Eds.), Digital intimate publics and social media (pp. 75-91). Springer.

Scannell, P. (2014). Television and the meaning of live: An enquiry into the human situation. Polity.

Sefton-Green, J. (2013). Learning at not-school: A review of study, theory, and advocacy for education in non-formal settings. MIT Press.

Sefton-Green, J., \& Erstad, O. (Eds.) (2019). Learning beyond the school: International perspectives on the schooled society. New York: Routledge.

Vannini, P., \& Williams, P. (Eds.). (2009). Authenticity in culture, self and society. Ashgate. 